\title{
Financial Market Integration in Late Medieval Europe: Results from a Threshold Error Correction Model for the Rhinegulden and Basle Pound 1365-1429
}

\author{
Peter Kugler ${ }^{a}$
}

JEL-Classification: N23

Keywords: Financial market integration, transaction costs, threshold error correction, Basle pound, Rhinegulden

\section{Introduction}

Under strict convertibility the silver and gold currencies of the past offered arbitrage opportunities between the markets for silver and gold bullion and the foreign exchange market. In a frictionless world the exchange rate between two currencies based on the same precious metal would have to exactly reflect their metallic content. For silver and gold currencies, the relative price of silver and gold bullion also exerts a significant impact on their exchange rates. In order to illustrate the arbitrage operations in a bimetallic system, let us assume that there is an excess supply of gold and that the price of gold relative to silver falls below the mint ratio. These conditions allow profit making by having gold coined and exchanging the gold coins for silver coins which are then melted down and sold on the silver market. The theory of bimetallic systems without transaction costs, which is outlined by NieHans (1978, pp. 153-158) and Velde and Weber (2000), is a good approximation of how bimetallism worked in the $19^{\text {th }}$ century. However, in preindustrial times, in the presence of hazardous and costly transport routes and poor coin quality, such arbitrage operations were likely to be prevented by relatively high transaction costs. Indeed, bimetallism worked differently before the $19^{\text {th }}$ century, as discussed by Redish (2000) and Weber (2009). The former author reports that the seigniorage fees of the mint averaged around 5\% in medieval and early modern times. This figure presents a lower bound for transaction costs, as other costs were involved in these arbitrage operations. Thus, we expect a rather broad band of "arbitrage inactivity" for the exchange rate around its par value, derived from its metallic content and the silver-gold price ratio.

a Helpful comments of an anonymous referee are gratefully acknowledged. 
How large the deviation from equilibrium may be before profitable arbitrage operations correct them is an empirical question. Some recent papers address this issue. In particular, there are studies that consider the deviation of the exchange rate between two currencies from its par value defined by the relative silver or gold content. Most of these studies use threshold autoregressive models (TAR) in order to account for the transaction costs that prevented arbitrage of small differences between the exchange rate and its par value. Prakash and Taylor (1997) and Canjels, Prakash and Taylor (2004) consider the classic gold standard period from 1879 to 1913 and the dollar/pound exchange rate; FLANDrEaU (2002) provides an analysis of the case of the bimetallic French franc during the $19^{\text {th }}$ century; and VolcKart and Wolf (2006) analyze the relationship between the silver currencies of Flanders, Lübeck and Prussia from 1310 to 1490.

The work of Prakash and Taylor (1997, Table 5) indicates that deviations from par values were possible only in the range of $0.15-0.46 \%$ until arbitrage operations were triggered in the classic gold standard. This finding is not surprising, as the introduction of the telegraph, the steamship and the railroad as well as the improved safety of transport routes significantly decreased the transaction costs of exploiting arbitrage by shipping precious metals during the $19^{\text {th }}$ century. For the silver currencies of Flanders, Lübeck and Prussia, from 1385 to 1450, VOLCKART and WoLF (2006) find larger bands of arbitrage inactivity within the range of 0.34 and $0.99 \%$. However, the difference is surprisingly small, as we would expect the information and transport revolution in the second half of the $19^{\text {th }}$ century to have led to a huge decrease in transaction costs. Thus, it is important to analyze other data on financial market integration of late medieval and early modern times.

This paper uses data for the Basle silver pound (equal to 240 pennies) and the golden Rhinegulden for the period 1365-1429. This data from a rather turbulent period of Basle's history reveals sizeable variations in the monetary value of the Basle penny, as it was debased several times and revalued for political reasons during this period ${ }^{1}$. In our study, as the relative price of gold and silver bullion and the exchange rate between the Basle pound and the Rhinegulden could adjust in order to restore equilibrium, we apply a threshold vector error correction model instead of a TAR model. This framework not only allows us to estimate how large the deviations have to be in order to trigger arbitrage operations, it also provides information about the extent to which the two markets (foreign exchange, gold/silver bullion) adjust.

1 The history of the Basle pound during the late middle ages, and the results of a VAR analysis of the gold and silver prices as well as the silver-gold ratio is reported by Weber (1996). Moreover, he has generously provided the data series used in this study. 
The paper is organized as follows: Section 2 contains a brief account of the history of Basle and its currency in late medieval times. The econometric model and the data used are described in Sections 3 and 4. The results are reported in Sections 5 and 6, and Section 7 concludes.

\section{Historical Background: Political Developments, Monetary System and Fiscal Policy}

In this section, a brief account of the historical background, the monetary system and the fiscal policy of medieval Basle is given. For more details, the reader is referred to Rosen (1972, in particular for fiscal policy) and Weber (1996, in particular for the monetary system). In late medieval times, Basle was a rather important trading town: The first permanent bridge over the Rhine was built in Basle in 1225 , and it was a nodal point at the trade routes connecting the economic centers north and south of the Alps. The town was relatively large with a population of 8,000 to 10,000 inhabitants, similar in size to Frankfurt am Main or Strasbourg. In the $14^{\text {th }}$ century, the town was hit by two large disasters; namely, the plague in 1349 and a devastating earthquake and fire in 1356 that destroyed nearly all its wooden structures. However, the town recovered quickly from these two shocks, and the rebuilding of it led to an economic boom. Politically, the town was a member of the Holy Roman Empire, and the late medieval period was characterized by attempts of France, the Austrian Habsburgs and the Swiss League to get it under their control. These conflicts were superimposed by the struggle between the Bishop and the nobility on the one hand, and the citizens organized in trade guilds on the other hand. In 1374, the trade guilds took over power from the Bishop and the local nobility, who, however, restored the aristocratic order with the help of the Austrian Habsburgs in 1375. The trade guilds were readmitted in the city council a few years later. The battle of Sempach in 1386 with the defeat of the Habsburgs against the Swiss League marks the end of the Austrian influence in Switzerland and the beginning of the dominance of the trade guilds in Basle.

The monetary system of medieval Basle consisted of a local silver pound which was subdivided into 20 shillings and 240 pennies $^{2}$. However, only the silver penny

2 Many pound units of account were used in Europe during the Middle Ages (Spufford, 1988, pp.411-414). The Troyes pound is probably the most well known. The pound should correspond to the Roman pound (libra $=327$ gr.) of silver, but different currency issuers (sovereigns, bishops, towns) assumed different values for the Roman libra. 
was minted, while the shilling and pound existed solely as a unit of account. Apart from this local money, other coins that were accepted in international transactions circulated. In particular, the Rhinegulden (a 3.5 g. gold coin) was important for large commercial transactions at that time in Basle. Although money was based on a metallic standard in the Middle Ages, coins were often debased by rulers or other bodies possessing the right to issue currency, resulting in transitory inflationary episodes. The data reported by Bernholz (2003, p. 28), show instances of the heavy depreciations of 12 local currencies all over Europe against the stable Florin (3.5 g. gold coin issued by republic of Florence) from 1300 to 1500 . Most of these debasements were caused by fiscal problems and seigniorage motives. However, the case of Basle is different: The data collected by Rosen (1972, pp. 5-9) show that fiscal policy followed a medium-term balanced budget rule in late medieval times. Temporary budget deficits were financed by borrowing, and the state even accepted money offered by investors to buy an annuity. Therefore, the seigniorage motive is not plausible for the case of medieval Basle. Nevertheless, we have a series of debasements and revaluations of the Basle penny from 1373 to 1403 for political reasons. The city council bought the right of coinage from the Bishop in 1373 for 4,000 pounds, and this right was repeatedly used as an instrument in local political conflicts. When the trade guilds dominated the city council, there were several debasements, as the income from land property and the feudal privileges of the nobility was fixed in nominal terms. By contrast, when the nobility dominated the city council, there was a revaluation of the penny. In 1403, Basle joined the monetary union of Southern Germany and Switzerland (Rappenmünzenbund), and the penny was revalued. Another motive for some debasements was the stabilization of the pound price of gold, which was the exchange rate vis-à-vis internationally accepted gold currencies such as Rhinegulden, Florin and Ducat. These changes accommodated the exogenous changes in the silver-gold ratio that were brought about by gold imports from Africa and the increased output of Hungarian mines (Weber, 1996, p. 485). 


\section{Data}

The data used in this study are provided by WeBER (1996) and are a by-product of the analysis of the financial accounts of Basle from 1360-1535 by J. Rosen $(1972,1989)^{3}$. This data source records the expenditure and income items in Basle pounds, in pennies, and often in the equivalent amount of Rhinegulden. These three figures and the knowledge of the silver and gold content of the two currencies allow us to calculate the pound price of silver $(P S)$ and gold $(P G)$ as well as the ratio of the quantities of physical gold and silver $(P S G)$ for each budget item $^{4}$. Averaging the data of all these transactions within a year provides us with the three time series displayed in Figures 1-3.

The pound price of gold can be considered as the nominal exchange rate between pound and Rhinegulden. If we divide the pound price of gold by that of silver, we get a kind of real exchange rate between the two currencies. In an arbitrage-free world, the silver-gold ratio and the above-defined real exchange rate have to be equal: $\log (P G)-\log (P S)=\log (P S G)$. However, transaction costs were sizable in medieval times, as transport of precious items on notoriously dangerous routes was very risky. This suggests that small deviations between the two variables could persist, but large deviations would lead to arbitrage operations.

Both nominal prices displayed in Figure 1 and 2 appear to be non-stationary and have an inflationary trend. However, they seem to be cointegrated, as the real exchange rate displayed in Figure 3 shows no trending behavior. In addition, Figure 3 shows that the real exchange rate and the silver-gold ratio are apparently closely related, but not identical. The difference between the two series can be interpreted as a gold premium or an undervaluation of the Basle pound. In the first 25 years of our sample, capital flight triggered by political conflicts and debasements led to a weak Basle pound and a positive gold premium. The liberalization and suspension of the feudal trade barrier after the defeat of the nobility in 1386 stimulated local production and led to a correspondingly stronger Basle pound and a tendentially negative gold premium. Figure 4 shows the histogram of the absolute values of the $(\log )$ gold premium, which has a mean of 0.05 and lies in a range between 0 and 0.22 . This is clearly larger than the deviations in the approximate range of 0.02 to 0.06 reported by VolcKart and Wolf (2006, pp. 131) for the silver currencies of Flanders and Northern Germany from 1385 to 1490.

3 Earlier data are not available, as the archives of the city of Basle were destroyed in the earthquake. Rosen (1989) contains all the publications of the author on public finance in mediaeval Basle in German. Rosen (1972) is an English translation of the most important article within this collection.

4 For details, the reader is referred to the appendix of the article by Weber (1996, p. 491). 
Figure 1: Log Basle Pound Price of a Gram of Gold 1365-1429

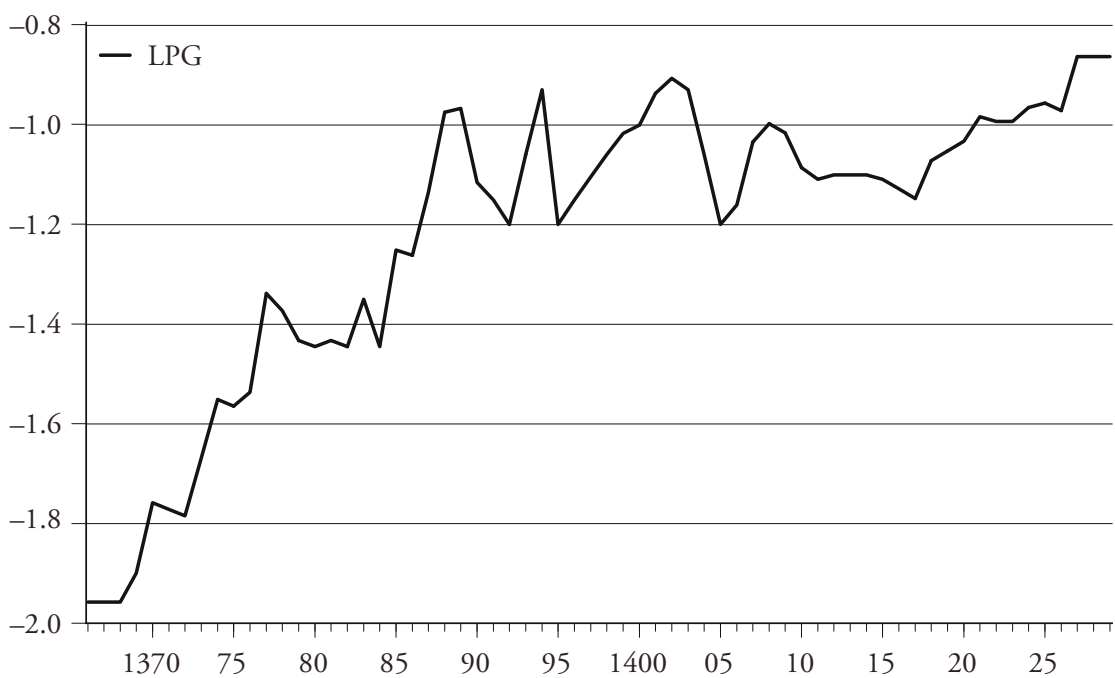

Figure 2: Log Basle Pound Price of a Gram of Silver 1365-1429

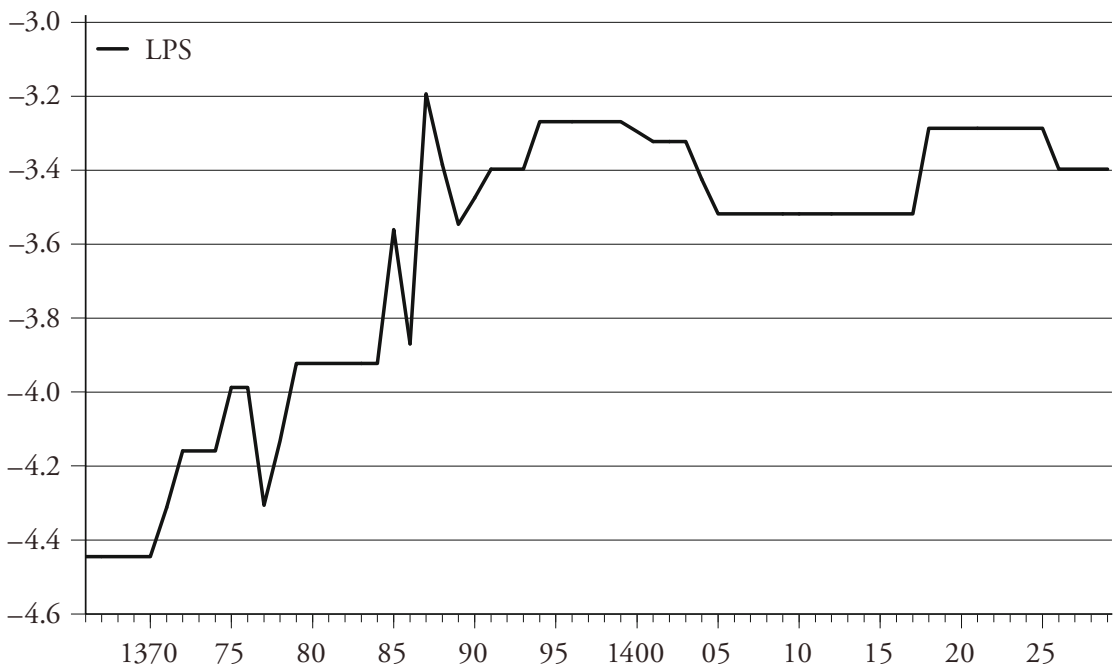


Figure 3: Real Exchange Rate of the Basle Pound against the Rhinegulden and the Silver-Gold Ratio 1365-1429

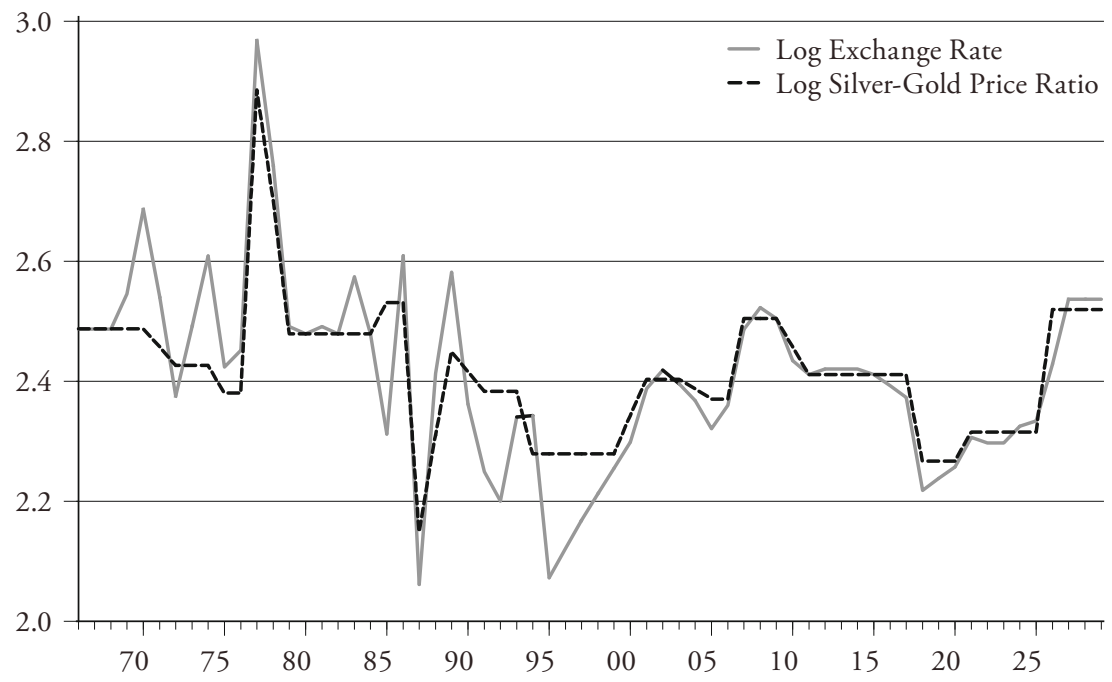

Figure 4: Histogram of the Absolute Difference between the Real Exchange Rate of the Basle Pound against the Rhinegulden and the Silver-Gold Ratio (Gold Premium) 1365-1429

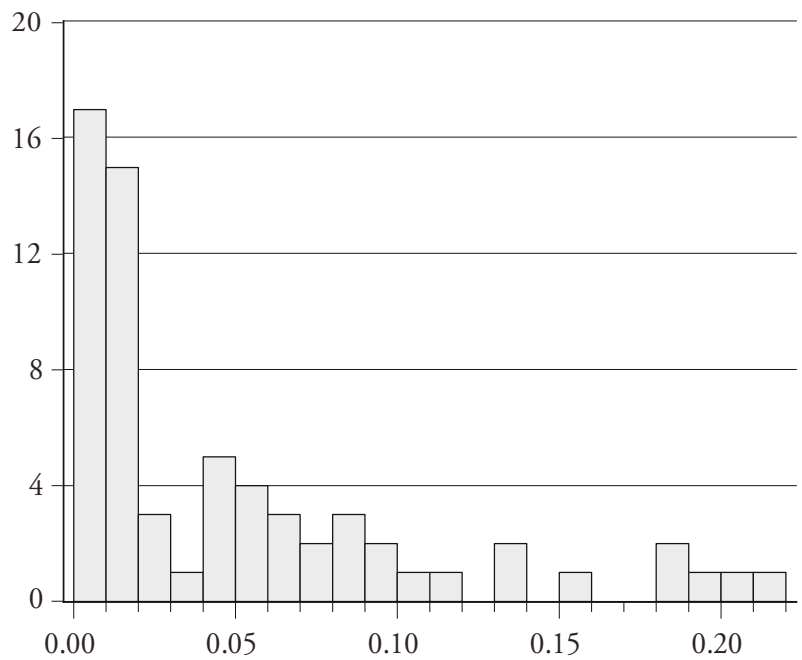

Series: $A B S\left(\log \left(\frac{\frac{P G}{P S}}{P S G}\right)\right.$

Sample 1365-1429

65 Observations

Mean

0.050538

Median

0.023285

Maximum

0.219243

Minimum

$2.21 \mathrm{e}-05$

Std. Dev.

0.056896

Skewness

1.456344

Kurtosis

4.323652

Jarque-Bera 27.72197

Probability $\quad 0.000001$
0.00
0.10
0.15
0.20 


\section{Econometric Model}

Now let us turn to the econometric model used in this study. Let $x$ and $y$ be the log real exchange rate and the log silver gold ratio, respectively, and define the $\log$ difference as $z=x-y$. We apply the following threshold (vector) error correction model for these series ${ }^{5}$ :

$$
\begin{aligned}
& \Delta x_{t}=a_{1}+\lambda_{1} z_{t-1}+\varepsilon_{1 t}, \quad \text { if } a b s\left(z_{t-1}\right)<\tau \\
& \Delta x_{t}=a_{1}+\lambda_{2} z_{t-1}+\varepsilon_{1 t}, \text { if } a b s\left(z_{t-1}\right) \geq \tau \\
& \Delta y_{t}=a_{2}+\lambda_{3} z_{t-1}+\varepsilon_{2 t}, \text { if } a b s\left(z_{t-1}\right)<\tau \\
& \Delta y_{t}=a_{2}+\lambda_{4} z_{t-1}+\varepsilon_{2 t}, \text { if } a b s\left(z_{t-1}\right) \geq \tau \\
& \lambda_{1}, \lambda_{2} \leq 0 ; \lambda_{3}, \lambda_{4} \geq 0 .
\end{aligned}
$$

If transaction costs are relevant, we expect $\lambda_{1}=\lambda_{3}=0$ and at least one of the two other error correction coefficients to be different from zero. An intercept term, which is common across the two regimes, is included in the model. As the two series have no trend, the constant term can only arise from an intercept term in the cointegrating combination $(z=y-x+c)$ indicating a non-zero long-run equilibrium value for $z$. The intercepts could be made regime-dependent, too. In our application, they are statistically insignificant, and the results only change marginally if we estimate the model with no or with two regime-dependent intercepts.

Defining a dummy variable $d$, which is one when $a b s\left(z_{t-1}\right)<\tau$ holds and otherwise 0 , we can rewrite our model in two equations:

$$
\begin{aligned}
& \Delta x_{t}=a_{1}+\lambda_{1} z_{t-1} d_{t-1}+\lambda_{2} z_{t-1}\left(1-d_{t-1}\right)+\varepsilon_{1 t} \\
& \Delta y_{t}=a_{2}+\lambda_{3} z_{t-1} d_{t-1}+\lambda_{4} z_{t-1}\left(1-d_{t-1}\right)+\varepsilon_{2 t}
\end{aligned}
$$

These two equations can be estimated by OLS when $\tau$ is known. In order to determine this parameter, we use a grid search over the possible interval ${ }^{6}$ to get the value which minimizes the determinant of the residual covariance matrix of

5 This modeling framework was developed by BALKE and Fомвy (1997) for cointegrated series with non-linear adjustment dynamics. It is applied to analyze commodity market integration in the $19^{\text {th }}$ century by EJRnaEs and Persson (2000) as well as JaCKs (2005).

This model can be directly applied to stationary series (as indicated to be the case) when the cointegration coefficients are known to be one, as in our case.

6 The range of $\tau$ is restricted to values between $10 \%$ and $90 \%$ quantiles of the absolute values of $z$. 
system (2). The parameter $\tau$ is only identified if this non-linearity is present. In order to test this, we adopt the approach developed by TsAY (1989) for testing the appropriateness of a TAR specification based on "arranged" AR(1) models. This approach is applied twice, namely to both linear EC-equations. In this framework, the observations are ordered in ascending or descending order of the regressor (lagged $z$ in our case) and then parameter stability is tested using the Chow or CUSUM test. The Chow test is applied with two breakpoints for absolutely large negative values and large positive values. The threshold structure implies that the model does not exhibit parameter stability. Moreover, Tsay suggested a test based on the recursive residuals of this arranged AR model: The recursive residual is regressed on the lagged regressor, and the corresponding coefficient is tested to be zero as implied by linearity.

\section{Regression Results}

Before turning to the estimation results for the threshold EC-model, we report some preliminary test results. Table 1 provides us with the findings of the Phillips-Perron unit root test and the Kwiatkowski-Phillips-Schmid-Shin stationarity test. The results of several stability tests applied to the two arranged EC equations as well as those of the Tsay test are reported in Table 2.

Table 1: PP Unit Root Test and KPSS Stationarity Test Results, Log Real Exchange Rate and Log Silver-Gold Ratio, Basle 1365-1429

\begin{tabular}{lcc}
\hline & PP & KPSS \\
\hline Log real exchange rate & $-4.1342^{* *}$ & 0.3555 \\
Log silver-gold ratio & $-4.0647^{* *}$ & 0.3095 \\
\hline
\end{tabular}

Bartlett kernel, bandwith 5; * and ** denotes significance at the 5\% and 1\% level, respectively

Table 1 points clearly to stationarity of the two series: The unit root hypothesis can be clearly rejected at the $1 \%$ level, whereas the stationarity hypothesis cannot be rejected at the 5\% level. Although the log pound price of silver and gold are both indicated to be non-stationary, they appear to be cointegrated leading to a stationary real exchange rate. 
Table 2: Non-Linearity Tests for Arranged Linear EC Equations for Log Exchange Rate $(x)$ and Silver-Gold Ratio $(y)$, Basle 1365-1429

$$
\begin{aligned}
& \Delta x_{t}=a_{1}+\lambda_{1}\left(x_{t-1}-y_{t-1}\right)+\varepsilon_{1 t} \\
& \Delta y_{t}=a_{2}+\lambda_{3}\left(x_{t-1}-y_{t-1}\right)+\varepsilon_{2 t} \\
& \text { observations in ascending order of }\left(x_{t-1}-y_{t-1}\right)
\end{aligned}
$$

\begin{tabular}{lcc}
\hline & $\Delta x_{t}$ & $\Delta y_{t}$ \\
\hline Chow-Test & 2.5967 & 2.6381 \\
$\mathrm{~F}(4,56)$ break at $8^{\text {th }}$ and $55^{\text {th }}$ observation & $(0.0459)$ & $(0.0433)$ \\
CUSUM Test significant at & $5 \%$ & $10 \%$ \\
Tsay-test (single equation) & 5.1529 & 4.1575 \\
$\mathrm{~F}(1,57)$ & $(0.0250)$ & $(0.0437)$ \\
Tsay-test (joint) & 9.3100 & \\
$\chi_{2}^{2}$ & $(0.0095)$ & \\
\hline
\end{tabular}

Marginal significance in parentheses beneath test statistics

The test results reported in Table 2 clearly point to a non-linear error correction model and support our threshold specification. Firstly, the hypothesis of parameter stability is always rejected (at least at the 10\% level) by the Chow and CUSUM tests for both arranged linear error correction equations. This indicates that absolute large regressor values have different effects than small ones. Secondly, the Tsay test based on a regression of the arranged regression recursive residual on the regressor is separately as well as jointly significant for both equations. This leads to a clear rejection of the linearity hypothesis.

The estimation results that we obtained for the optimal $\tau$ which was 0.074 , approximately 7.4 percent, are as follows (standard errors below coefficient estimates in parentheses):

$$
\begin{aligned}
& \Delta x_{t}=-0.002116+0.3193 z_{t-1} d_{t-1}-0.9379 z_{t-1}\left(1-d_{t-1}\right) \\
& \begin{array}{lll}
(0.01665) \quad(0.6023) \quad(0.2312)
\end{array} \\
& R^{2}=0.2141, \quad D W=2.0697 \\
& \Delta y_{t}=0.000992+0.7135 z_{t-1} d_{t-1}-0.2019 z_{t-1}\left(1-d_{t-1}\right) \\
& \begin{array}{lll}
(0.01251) \quad(0.4548) \quad(0.1753)
\end{array} \\
& R^{2}=0.05685, \quad D W=2.1255
\end{aligned}
$$


These estimates tell us that there is no adjustment of the exchange rates if the deviation is smaller than 7.4 percent in absolute value. That is, both error correction coefficients are low and statistically not different from zero at any reasonable significance level for the first regime. For larger deviations, we obtain an asymmetric adjustment with all the change taking place with the exchange rate within one year. The error correction coefficient for the silver-gold ratio is wrongly signed and statistically not different from zero at any reasonable significance level. However, the error correction coefficient of the real exchange rate is negative (as it should) and highly statistically different from zero and almost equal to one. Thus, large deviations of the two variables are fully corrected by a change in the real exchange rate within a year.

It is interesting to compare the TEC results with those of the usual linear EC model. These results are given by

$$
\begin{aligned}
& \Delta x_{t}= 0.00077-0.7763 z_{t-1} \\
&(0.01688) \quad(0.2217) \\
& R^{2}= 0.1651, \quad D W=2.1322 \\
& \Delta y_{t}=0.000499-0.0843 z_{t-1} \\
& \quad(0.01272) \quad(0.1670) \\
& R^{2}=0.00409, \quad D W=2.2320
\end{aligned}
$$

This model leads to the conclusion that we have a gradual adjustment of the exchange rate and no reaction of the silver-gold ratio. Thus, we arrive at the same conclusion with respect to the variable which adjusts to disequilibrium, but the impression of a gradual adjustment process is wrong.

Finally, we could ask which of the two nominal prices adjust and to what extent. To answer this question, we estimated the TEC model with the nominal gold price $(x x)$ and nominal silver price $(y y)$ as the right-hand variable:

$$
\begin{aligned}
& \Delta x x_{t}=\begin{array}{ll}
0.01576-0.1985 z_{t-1} d_{t-1}-0.2660 z_{t-1}\left(1-d_{t-1}\right) \\
(0.009939)
\end{array} \quad(0.3614) \\
& R^{2}=0.0607, \quad D W=1.9264 \\
& \Delta y y_{t}=0.01788-0.5178 z_{t-1} d_{t-1}+0.6719 z_{t-1}\left(1-d_{t-1}\right) \\
& \begin{array}{ll}
(0.015422) & (0.5606)
\end{array} \\
& R^{2}=0.1474, \quad D W=2.4339
\end{aligned}
$$


These estimates suggest that both nominal variables adjust when deviations from equilibrium are large. Interestingly, the larger part of the adjustment runs over the silver price, where we find a clearly larger (absolute value) error correction coefficient. Thus, decreases and increases in the silver content of the penny by the city council appear to be also driven by deviations of the real exchange rate from the silver-gold ratio. Note that the sum of the absolute EC coefficients is approximately one; i.e., adjustment to equilibrium takes place within one year. It may be worthwhile to note that the EC-coefficients estimates for the linear specification are -0.257 and 0.519 , respectively, indicating a clearly slower adjustment than the second regime of the non-linear specification.

\section{Bootstrap Replications}

The analysis carried out so far has two drawbacks: Firstly, it gives no information on the sample variation of the threshold estimate. Secondly, the covariance matrix estimate for the EC coefficients is obtained on the assumption that the threshold value is known. In order to get some information on the relevance of these issues, we run 1,000 bootstrap replications of our TEC model. The mean, standard deviation, median and the $5 \%$ and $95 \%$ quantiles obtained by this exercise are reported in Table 3 . We get qualitatively the same results with respect to the EC coefficients, even if the sample variation is indicated to be higher (as is expected). Only the coefficients of the real exchange rate are significantly negative (measured by their standard deviation or by the $90 \%$-confidence interval), whereas for the other three adjustment coefficients, this is not the case. In addition, the mean and median bootstrap estimate of the threshold is similar to that reported before. However, the standard deviation and the 90\%-confidence interval show a rather large sample variation.

The estimated threshold is much larger than the values estimated by PraKasH and TAYLOR (1997) for the dollar/pound exchange rate under the classical gold standard as well as by Volckart and Wolf (2006) for the silver currencies of Flanders, Lübeck and Prussia, respectively, for 1385-1450. The former result is not surprising given the information and transportation revolution in the second half of the $19^{\text {th }}$ century. The latter finding is rather surprising, as the differing results were obtained with medieval data. How can these differences be explained? Firstly, we should notice that our bootstrap exercise tells us that there is a lot of uncertainty with respect to the estimate of the threshold value obtained for the Basle pound data. As Volckart and Wolf used a different econometric technique (regime separation based on a random walk model for the "inactive" 
Table 3: Statistics for 1,000 Bootstrap Replications, Threshold Error Correction Model Log Real Exchange Rate $(x)$ and Silver-Gold Ratio $(y)$, Basle 1365-1429

$$
\begin{array}{ll}
\Delta x_{t}=a_{1}+\lambda_{1} z_{t-1}+\varepsilon_{1 t}, & \text { if } \operatorname{abs}\left(z_{t-1}\right)<\tau \\
\Delta x_{t}=a_{1}+\lambda_{2} z_{t-1}+\varepsilon_{1 t}, & \text { if abs }\left(z_{t-1}\right) \geq \tau \\
\Delta y_{t}=a_{2}+\lambda_{3} z_{t-1}+\varepsilon_{2 t}, & \text { if abs }\left(z_{t-1}\right)<\tau \\
\Delta y_{t}=a_{2}+\lambda_{4} z_{t-1}+\varepsilon_{2 t}, & \text { if abs }\left(z_{t-1}\right) \geq \tau \\
\lambda_{1}, \lambda_{2} \leq 0 ; \lambda_{3}, \lambda_{4} \geq 0 &
\end{array}
$$

\begin{tabular}{lccccc}
\hline & $\lambda_{1}$ & $\lambda_{2}$ & $\lambda_{3}$ & $\lambda_{4}$ & $\tau$ \\
\hline Mean & 0.5386 & -1.009 & 0.8972 & -0.2366 & 0.07800 \\
Std & 3.4448 & 0.4749 & 2.6276 & 0.3998 & 0.05002 \\
Median & 0.4777 & -0.9834 & 0.8632 & -0.2105 & 0.0717 \\
[Q05, & {$[-2.9348$,} & {$[-1.6194$,} & {$[-0.7231$,} & {$[-1.6319$,} & {$[0.01423$,} \\
Q95] & $5.259]$ & $-0.4835]$ & $0.1816]$ & $4.2875]$ & $0.1874]$ \\
\hline
\end{tabular}

range and no joint estimation of adjustment parameters and threshold), we have no comparable information on the precision of their threshold estimate. Secondly, the Basle data come from a very turbulent period with many, sometimes dramatic, de- and re-basements of the Basle pound and involve a gold-based currency with the Gulden. The data for the silver currencies of Flanders, Lübeck and Prussia are of a less turbulent period and show much less volatility. Thirdly, the lower transportation costs by sea for the pound Grote, and the Marks of Lübeck and Prussia than those by land between Basle and the archbishoprics of Cologne, Main and Treves as well as the palatinate, which issued the Rhinegulden, provide an additional potential explanation for the differing findings. Of course, these explanations are rather tentative, and it would be highly interesting to analyze other exchange rate data for the late medieval and early modern period. However, we should briefly mention some further evidence supporting high transaction costs in medieval financial markets, which are in line with our threshold estimate: Firstly, Spufford (1988, p. 394) and Homer and Sylla (2005, p. 76)

7 The standard errors for the threshold estimate reported by Volckart and Wolf (2006) are conditional on an a priori selected threshold value (median of absolute deviation from parity). This approach creates the problem of implicitly two estimates of the threshold (first stage for sample separation and second stage by applying OLS to only large deviations) and necessarily leads to an underestimation of sample variability of the threshold estimate. 
report that for money transfers by bill of exchange, which offered an alternative to the risky shipment of specie, up to $5 \%$ of the sum transferred was commonly charged. Secondly, the interest rate difference between commercial loans and bank deposits in Italy and the Netherlands (the financially most advanced regions in late medieval times) ranged from 5 to 15 percent in the period 1350 1450 (Homer and Sylla, 2005, Table 11, p. 136). Finally, we may mention that the application of our methodology to $16^{\text {th }}$ century data on the exchange rate of the Dutch Groat and the Spanish Ducado at two different market places (Seville and Medina del Campo) provides a threshold estimate of around 6\%, confirming the results reported above (Bernholz and Kugler, 2011).

\section{Conclusion}

This paper analyzes the financial market integration of the foreign exchange market for the Basle pound (a silver currency) and the Rhinegulden (a gold currency) and the market for gold and silver bullion. For this purpose, a threshold error correction model is applied. This analysis indicates that transaction costs prevent arbitrage when the difference of the gold-silver ratio and the real exchange rate is within a $7.4 \%$ band. For larger deviations from arbitrage equilibrium, real exchange rate movements close this gap within one year. The estimated threshold is much larger than the values estimated by Prakash and Taylor for the dollar/ pound exchange rate under the classical gold standard as well as by Volckart and Wolf for the silver currencies of Flanders and Northern Germany, respectively, over the period 1385-1450. The former result is not surprising given the information and transportation revolution in the second half of the $19^{\text {th }}$ century. The latter finding is rather surprising, as the differing results were both obtained with medieval data. The difference in the empirical findings are tentatively explained by the econometric techniques applied, the more turbulent monetary history of Basle in the period under consideration, the involvement of both a silver and a gold currency, as well as the lower costs of transportation by sea than by land. As these explanations are rather tentative, the analysis of other exchange rate data for the late medieval and early modern period is of considerable interest. 


\section{References}

Balke, N. S., and T. B. Fomby (1997), "Threshold Cointegration”, International Economic Review, 38 (3), pp. 627-645.

Bernholz, P. (2003), Monetary Regimes and Inflation; History, Economic and Political Relationships, Edward Elgar, Cheltenham UK.

Bernholz, P., and P. Kugler (2011), "Financial Market Integration in Early Modern Spain: Results from a Threshold Error Correction Model", Economics Letters, 110, pp. 93-96.

Canjels, E., G. Prakash-Canjels, and A. M. Taylor (2004), "Measuring Market Integration: Foreign Exchange Arbitrage and the Gold Standard, 1879-1913", The Review of Economics and Statistics, 86 (4), pp. 868-882.

Ejrnaes, M., and K. G. Persson (2000), "Market Integration and Transport Costs in France 1825-1903: A Treshold Error Correction Approach", Explorations in Economic History, 37, pp. 149-173.

Flandreau, M. R. (2002), "Water Seeks a Level: Modeling Bimetallic Exchange Rates and the Bimetallic Band", Journal of Money Credit and Banking, 34 (2), pp. 491-519.

Homer, S., and R. Sylla (2005), A History of Interest Rates (Fourth Edition), John Wiley.

JaCKs, D. S. (2005), "Intra- and International Commodity Market Integration in the Atlantic Economy, 1800-1913", Explorations in Economic History, 42, pp.381-413.

Niehans, J. (1978), The Theory of Money, Johns Hopkins University Press, Baltimore.

Prakash, G., and A. M. Taylor (1997), "Measuring Market Integration: A Model of Arbitrage with an Econometric Application to the Gold Standard, 1879-1913", NBER Working Paper 6073, June 1997.

Redish, A. (2000), Bimetallism: An Economic and Historical Analysis, Cambridge University Press, Cambridge.

Rosen, J. (1972), "Prices and Public Finance in Basle, 1360-1535", The Economic History Review, 25 (1), pp. 1-17.

Rosen, J. (1989), Finanzgeschichte Basels im späten Mittelalter, Stuttgart.

Spufford, P. (1988), Money and its Use in Medieval Europe, Cambridge.

Tsay, R. S. (1989), "Testing and Modeling Threshold Autoregressive Processes", Journal of the American Statistical Association, 82.

Volckart, O., and N. Wolf (2006), "Estimating Financial Integration in the Middle Ages: What Can We Learn from a TAR Model", The Journal of Economic History, 66(1), pp. 122-139. 
Velde, F. R., and W. E. Weber (2000), "A Model of Bimetallism”, Journal of Political Economy, 108 (6), pp. 1210-1234.

Weber, E. J. (1996), “'Imaginary' or 'Real' Moneys of Account in Medieval Europe? An Econometrics Analysis of the Basle Pound, 1365-1429”, Explorations in Economic History, 33, 1996, pp.479-495.

Weber, E. J. (2009), "Pre-Industrial Bimetallism: The Index Coin Hypothesis", World Economic History Congress, Utrecht.

\section{SUMMARY}

This paper analyzes the integration of the foreign exchange market for the Basle Pound and the Rhinegulden and the market for gold and silver bullion for the period 1365-1429. The application of a threshold error correction model indicates that transaction costs prevent arbitrage when the difference between the gold-silver ratio and the exchange rate is within a $7.4 \%$ band, whereas larger deviation exchange rate movements close this gap within one year. 